\title{
Hyperbilirubinemia in breastfed term neonates
}

\author{
Rashmi Ranjan Das
}

Received: 19 November 2011 / Accepted: 9 December 2011 /Published online: 30 December 2011

(C) Springer-Verlag 2011

\section{Dear Editor:}

I read with great interest the article by Chen et al. [3]. The authors conducted a study to identify risk factors associated with jaundice in exclusively breastfed term neonates and to guide clinicians regarding the management. The following points need some comment.

The authors found the overall hyperbilirubinemia rate $(\geq 15.0 \mathrm{mg} / \mathrm{dl}$ ) of $35.3 \%$. This rate is much higher than that described previously, in which the authors found $12 \%$ to $13 \%$ of breastfed babies with a bilirubin level of $\geq 12 \mathrm{mg} / \mathrm{dl}$ $[4,5]$. The possible explanations are as follows. The hyperbilirubinemic group had significantly higher TcB levels at nursery discharge and at OPD follow-up in the present study. Other risk factors for severe hyperbilirubinemia not reported in the present study are: blood group incompatibility, G6PD deficiency, previous sibling received phototherapy, male sex, infant of diabetic mother, East Asian race, etc. [1]. Besides these, supplementary feeding, weight loss percentage, and birth trauma significantly increase the risk of jaundice [2].

The description of length of stay in the nursery not being a major risk factor for hyperbilirubinemia in exclusively breastfed infants might not be true, as the authors have not excluded the above-reported risk factors. The current guideline suggests discharge at any time $<72 \mathrm{~h}$ significantly increases the risk for readmission to hospital and the risk for readmission with hyperbilirubinemia [1].
The authors also reported that a cesarean section cannot protect breastfed newborn infants from developing hyperbilirubinemia based on their observation. This might be true, as breastfeeding is often delayed in these infants due to the effect of pain and anesthesia in the mother, as well as other comorbidities for which cesarean section was performed.

To conclude, risk factors for jaundice in breastfed infants need to be clearly defined, so that affected infants can be diagnosed early and given timely treatment.

Conflict of interest None.

\section{References}

1. American Academy of Pediatrics, Subcommittee on Neonatal Hyperbilirubinemia (2004) Management of hyperbilirubinemia in the newborn infants 35 or more weeks of gestation. Pediatrics 114:297-316

2. Bertini G, Dani C, Tronchin M, Rubaltelli FF (2001) Is breastfeeding really favoring early neonatal jaundice? Pediatrics 107:E41

3. Chen YJ, Chen WC, Chen CM (2011) Risk factors for hyperbilirubinemia in breastfed term neonates. Eur J Pediatr. Jun 17 (In press)

4. Cloherty JP, Eichenwald EC, Stark AR (2009) Manual of neonatal care, 6th edn. Wolters Kluwer, New Delhi

5. Schneider AP 2nd (1986) Breast milk jaundice in the newborn. A real entity. JAMA 255:3270-3274

R. R. Das $(\bowtie)$

Department of Pediatrics,

All India Institute of Medical Sciences (AIIMS),

New Delhi 110029, India

e-mail: dr_rashmipgi@yahoo.com 